DOI: $10.4274 /$ jarem.galenos.2020.3145

J Acad Res Med 2020;10(2):143-8

\title{
Contribution of Fluorodeoxyglucose-Positron Emission Tomography Late Imaging to Diagnosis and Correlation with Histopathology in Invasive Lobular Breast Cancer
}

\author{
(1) Fikri Okan Falay, () Hülya Seymen \\ Koç University Faculty of Medicine, Department of Nuclear Medicine and Molecular Imaging, İstanbul, Turkey
}

Cite this article as: Falay FO, Seymen H. Contribution of Fluorodeoxyglucose-Positron Emission Tomography Late Imaging to Diagnosis and Correlation with Histopathology in Invasive Lobular Breast Cancer. J Acad Res Med 2020;10(2):143-8

\begin{abstract}
Objective: The aim of this study was to investigate the correlation between primary lesion and contralateral breast tissue metabolic parameters in standard and delayed images obtained on preoperative F-18-fluorodeoxyglucose (FDG) positron emission tomography (PET) and the correlation with pathological variables of primary lesion in invasive lobular breast cancer (ILC).

Methods: Seventeen ILC cases in which standard and late FDG-PET imaging were performed between 2007 and 2018 were included in the study. SUV $_{\text {max }}$ metabolic tumor volume (MTV) and total lesion glycolysis (TLG) values and change rates $(\Delta)$ of primary malignant lesion and contralateral breast control area were recorded. T and $\mathrm{N}$-stages, histological and nuclear grades of primary malignancy, estrogen receptor (ER), progesterone receptor, presence of human epidermal growth factor receptor (HER)-2 and Ki-67 values are compared with FDG-PET values.

Results: No statistically significant correlation was found between metabolic parameters and histopathological components of 17 ILC patients (median age: 45 years) after surgery (11 breast conserving surgery, 6 mastectomy). Among the metabolic parameters obtained from contralateral breast tissue, $S U V_{\text {max }}$-based ones [standard(s)-SUV max $_{\text {, late(g)-SUV }}$ max $\Delta S U V_{\text {max }}$ ] showed statistically significant differences with malignancy $(p<0.000)$.

Conclusion: Especially the negative median value of the control SUV $\mathrm{max}_{\max }$ suggests that late imaging may provide additional contribution, especially in the dense breast tissue, in the ILC with high probability of multifocality/multicentricity. Although there was no statistically significant difference with histopathological components, parallel results (such as high $\triangle$-TLG in presence of lymph node metastasis, HER-2 positive and high SUV ${ }_{\max }$ MTV and TLG median values in ER negative cases) were seen with the literature mostly consisting of invasive ductal carcinoma. Confirmation of this important information obtained only from ILC patients is required in multicentre studies or meta-analyzes in which the number of cases will be higher.

Keywords: FDG-PET, late imaging, metabolic parameter, invasive lobular cancer
\end{abstract}

\section{INTRODUCTION}

Breast cancer is the most common type of cancer in women and ranks second after lung cancer in cancer-related deaths. Early diagnosis, more accurate and intervention-free staging, treatment follow-up and determining prognosis are the most important processes in determining the approach to breast cancer. $50-70 \%$ of breast cancers are invasive ductal carcinoma (IDC), 5-15\% are invasive lobular cancer (ILC), 1-6\% mucinous carcinoma and 1-2\% tubular carcinoma (1).

In the diagnosis process, Magnetic resonance imaging is generally the method used especially in dens breast tissue and ILC, although it is required to have more sensitive non-invasive complementary

ORCID IDs of the authors: F.O.F. 0000-0003-4527-5983; H.S. 0000-0001-9799-2832. 
methods due to increasing unnecessary biopsy count because of low specificity (72\%), limitations in axillary lymph node staging and not being able to screen for distant metastases (2).

Although F-18-fluorodeoxyglucose-positron emission tomography (FDG-PET) imaging has a high sensitivity and specificity in showing malignant lesions, its sensitivity in breast cancer is limited. In metaanalysis, it is reported that the overall sensitivity of FDG-PET in detecting primary breast cancer is $64-96 \%$, specificity $73-100 \%$, positive predictive value $81-100 \%$, negative predictive value 52 $89 \%$ (3). While the sensitivity of FDG-PET is $57 \%$ in tumors smaller than $1 \mathrm{~cm}$ in diameter, it exceeds $90 \%$ in tumors larger than $1 \mathrm{~cm}$ in diameter (4). False positivity can be seen in benign lesions such as fibroadenoma, ductal adenoma and inflammation. However, there are also studies reporting that FDG-PET is better than conventional methods in the initial evaluation of patients, especially enabling the detection of infraclavicular, supraclavicular and internal mammarian lymph nodes and occult distant metastases (5).

Glut-1 and hexokinase expression, number of live tumor cells, histological subgroup, microvascular density and inflammatory cell presence in breast cancer are the major factors affecting FDG involvement (6). The main factors explaining low FDG involvement seen in ILCs are lower tumor cell density, diffuse infiltration in the surrounding tissue, low Glut-1 expression, and low proliferation rate (7). It is known that estrogen and progesterone receptor (PR) negative, HER-2 expression positive tumors show higher FDG involvement compared to receptor positive and HER-2 negative tumors (8).

The clinical systemic contribution of PET is reported to be low due to the low FDG affinity in mucinous (1-6\%) and tubular (1-2\%) cancers, which occur less frequently with ILC, which constitutes 10 $15 \%$ of breast cancers $(9,10)$. For these reasons, the contribution of FDG-PET to IDC was mostly evaluated in the studies, and the ILC was found in a limited number of studies or was not included in the study due to low sensitivity $(4,11)$.

The very low density of glucose-6-phosphatase enzyme in the tumor cell causes FDG to continue to accumulate. It is known that late imaging contributes to the diagnosis in malignancies, where the imaging quality will be optimal as much as the radiopharmaceutical half-life allows (12). There are many studies reporting that late image in FDG-PET in breast cancer significantly increases sensitivity and specificity (13-26). However, these studies mostly consist of IDC patients.

As the breast tissue density increases, FDG involvement is higher, and in this case primary lesion visualization has a negative effect on the ILC with low FDG involvement potential. In this retrospective study, it was aimed to investigate the contribution of metabolic parameters obtained from primary lesion and contralateral breast tissue and late images taken in preoperative FDG-PET in the ILC, where clinical diagnosis and staging of breast cancer is particularly difficult, to predict diagnosis and also the correlation of histopathological variables with primary lesion.

\section{METHODS}

Seventeen patients diagnosed with ILC applied to the nuclear medicine, molecular imaging and radionuclide treatment department for staging in purpose of FDG-PET test between 2007 and 2018, who underwent surgery for breast and axilla within 5-30 days after FDG-PET were included in the study. 5070 minimum after 5-9 mCi FDG given intravenously, standard 7-9 bed length and between vertex and mid-crus and; 160 200 minimum later, late imaging of 2 bed areas covering the neck and thorax regions made with GE Discovery 1Q-5 ring and GE Discovery 710 PET/computed tomography devices. The images were evaluated with the PETVCAR program at GE AW workstation. Metabolic tumor volume (s-MTV, g-MTV) and total lesion glycolysis (s-TLG, g-TLG) semicantitative tissue analysis values and exchange rates $(\Delta=$ late draft value-standard draft value/standard draft value $\times 100$ ) calculated from the area of interest drawn according to the relative threshold of $40 \%$ and above of SUV max were recorded with primary malignant lesion SUV max $_{\text {max }}$ [standart(s)-SUV max $_{\text {max }}$ late(g)-SUV $V_{\text {max }}$ values. In the presence of multifocal/multicentric malignancy, the lesion with the highest $S U V_{\text {max }}$ was included in the study. As the control group, the same semi-quantitative tissue analysis values and change rates were obtained from the area of mirror image in the opposite breast parenchyma. $\mathrm{T}$ and $\mathrm{N}$-stages of primary malignancy, histological and nuclear grades, estrogen receptor (ER), PR, presence of human epidermal growth factor receptor (HER)-2 and Ki-67 values obtained from pathology of mastectomy (6 patients) or breast-conserving surgery (11 patients) are evaluated with semi-quantitative tissue analysis results obtained from FDG-PET. The presence of the estrogen or PR ( $1 \%$ and above) was considered as receptor positivity. The fact that $\mathrm{Ki}-67$ was $14 \%$ and above was classified as a high proliferation index. HER-2 overexpression was evaluated as immunohistochemically positive, and HER-2 amplification was detected by fluorescent in-situ hybridization method in cases with $0 / 1+$ immunohistochemistry.

\section{Statistical Analysis}

Since the data did not conform to the normal distribution, given as median and interval, in the dependent variable analysis (between the patient and healthy breast) Wilcoxon sign order test is used; Mann-Whitney $U$ test was used only as an independent variable analysis for comparing the patient group within itself. $\mathrm{P}<0.05$ was accepted as the statistical significance limit.

The primary outcome measure of the study is to investigate whether late imaging FDG involvement in the ILC contributes to the diagnosis prediction; secondary outcome measure is the relationship of FDG involvement amount with metastasis and histopathological variables (histological and nuclear grade, ER, PR and HER-2 presence, Ki-67). 


\section{Ethical Approval and Informed Consent}

The study was conducted in accordance with the World Medical Association Declaration of Helsinki "Ethical Principles for Medical Research Involving Human Subjects" (amended in October 2013) and the authors declared that the study was carried out with ethical principles in accordance with the Helsinki Declaration. Patient consent could not be obtained due to the retrospective study structure.

\section{RESULTS}

Demographic features and histopathological characteristics of 17 patients included in the study, which were undergo surgery with the diagnosis of ILC, are presented in Table 1. After median 32 days $(30 \pm 28$ days), breast protecting surgery was performed in 11 patients $(76 \%)$ and mastectomy (24\%) in 6 patients. Ten of the cases are pT1, 6 of them are pT2, and only 1 patient is pT3.

The comparison of the primary malignancy and control tissue analysis values of the cases obtained in FDG-PET is given in Table 2. Accordingly, a significant difference was observed in the values obtained from the control interest area with malignancy in the SUV $V_{\max }$ based values of s-SUV $V_{\max }$ g-SUV $V_{\max }$ and $\triangle-S U V_{\max }$. In addition, the negative rate of median change in the control group in $\triangle-S U V_{\max }$ and $\triangle-T L G$ indicates that the difference in involvement between the non-malignant breast parenchyma and malignancy has increased in the late image (Figure 1).

Of the 7 cases with lymph node metastasis, the patient with the highest SUV $\max$ value in the group, metastatic lymph node was visualized in the late image and the primary malignancy $\triangle-S U V_{\text {max }}$ value was 62 (Figure 2).

\section{DISCUSSION}

Diagnosis of ILC and staging distant metastasis with lymph node after diagnosis is one of the most clinically difficult malignancies. The most important reasons for this are the fact that the tumor is seen as a tissue thickening rather than a mass formation due to the fact that it does not cause a stromal reaction and rarely observed microcalcification, which is the most important clinical finding in early diagnosis (27-29).

It is known that invasive triple negative tumors (TNT) in breast cancer have higher FDG affinity than non-TNTs (30) and grad 3 tumors have higher FDG affinity compared to grade 1-2 tumors (31). In addition, as well as tumor histopathology, microvascularization and hypoxia level affect FDG-PET radiopharmaceutical affinity (32).

There are many factors such as low tumor cell density, diffuse infiltration in the surrounding tissue, low Glut-1 expression, and low proliferation rate, explaining the low FDG involvement of FDG-PET in ILCs.

Many different metabolic parameters such as SUV, MTV, TLG have been used to increase sensitivity and specificity in breast tumors.
Table 1. Demographic characteristics and histopathological characteristics of invasive lobular cancer cases $(n=17)$

\begin{tabular}{|c|c|}
\hline \multicolumn{2}{|l|}{ Age - year } \\
\hline Median (range) & $45(35-62)$ \\
\hline \multicolumn{2}{|l|}{ T-stage (n, \%) } \\
\hline T1 & $10(59)$ \\
\hline T2 & $6(35)$ \\
\hline T3 & $1(6)$ \\
\hline \multicolumn{2}{|l|}{$N$-stage $(n, \%)$} \\
\hline NO & $10(59)$ \\
\hline N1 & $7(47)$ \\
\hline \multicolumn{2}{|l|}{$\operatorname{ER}(n, \%)$} \\
\hline+ & $10(59)$ \\
\hline- & $7(41)$ \\
\hline \multicolumn{2}{|l|}{ PR (n, \%) } \\
\hline+ & $10(59)$ \\
\hline- & $7(41)$ \\
\hline \multicolumn{2}{|c|}{ Nuclear grade (n, \%) } \\
\hline 1 & $5(29)$ \\
\hline 2 & $8(47)$ \\
\hline 3 & $4(24)$ \\
\hline \multicolumn{2}{|c|}{ Histological grade (n, \%) } \\
\hline 1 & $5(29)$ \\
\hline 2 & $8(47)$ \\
\hline 3 & $4(24)$ \\
\hline \multicolumn{2}{|l|}{ HER-2 (n, \%) } \\
\hline+ & $9(53)$ \\
\hline- & $8(47)$ \\
\hline \multicolumn{2}{|l|}{ Ki-67 (n, \%) } \\
\hline High ( $\geq 14)$ & $11(65)$ \\
\hline Low $(<14)$ & $6(35)$ \\
\hline
\end{tabular}

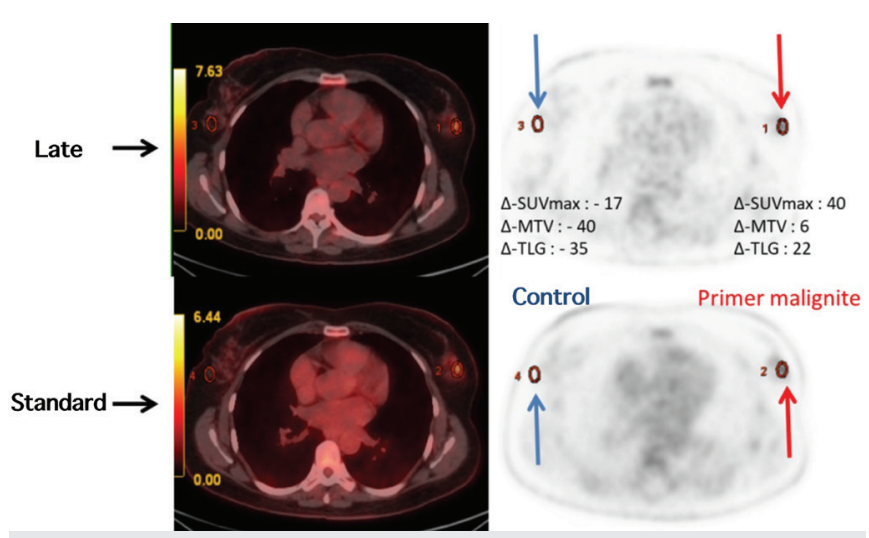

Figure 1. Fluorodeoxyglucose-positron emission tomography standard and late images; Left breast lower-inner quadrant invasive lobular cancer interest (red arrow) and contralateral breast same quadrant interest (blue arrow) MTV: Metabolic tumor volume, TLG: total lesion glycolysis 
The majority of cases are more common IDC in nearly all of the researches. In 6 studies investigating the contribution of late imaging with FDG-PET in breast cancer, the first bibliography of $2 / 56,3 / 66,13 / 86,2 / 53,8 / 48$ and $2 / 38$, respectively, was included in the studies and the rate was only $9 \%(30 / 347)(18-20,24-26)$. There is no study of ILC cases.

The correlation of tumor heterogeneity with aggressive malignancy has been demonstrated in many tumors. In the study of Garcia-Vicente et al. (19), it was predicted that increase in heterogeneity in late images may provide more meaningful prognostic information (18). In our study, $\triangle$-TLG value to be 50 (median: 9) in our 2 cases who had lymph node metastasis is a finding that supports this.

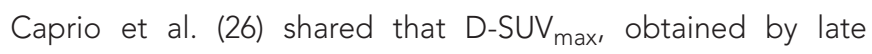
imaging of FDG-PET in 8-ILC, 40-IDC and 11 benign breast lesions, increased significantly in malignancy and decreased significantly in benign lesions (25). In cases with local recurrence and distant metastasis, 13 of them were ILC and 86 of them were invasive breast cancer, Hildebrandt et al. (21) reported that more malignancy could be detected by decreasing background activity in late images (20).

Breast density can vary widely with age and weight. The higher FDG involvement in the dens breast tissue is a reason that reduces sensitivity in the ILC, which can show low FDG affinity. In our study, the control $\triangle-S U V_{\max }$ median value obtained from the contralateral breast tissue is -10 . In our study, in which $\Delta-S U V_{\text {max }}$ (median: 53) was significantly different in ILC, it was thought that late imaging may contribute additionally to the visualization of the ILC, which has a high probability of multifocality/multicentricity, especially in the dense breast tissue.

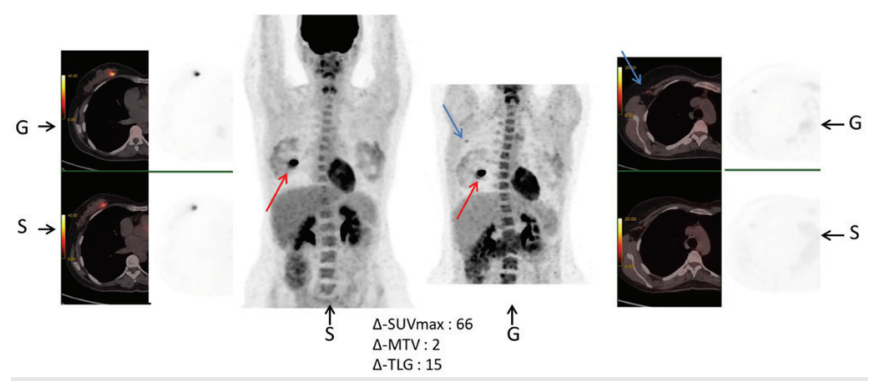

Figure 2. Fluorodeoxyglucose (FDG)-positron emission tomography standard (S) and late (G) images; Right breast lower-inner quadrant invasive lobular cancer (red arrow), FDG involvement in late image visualized in the right central axillary metastatic lymph node (blue arrow)

MTV: Metabolic tumor volume, TLG: total lesion glycolysis
Garcia-Vicente et al. (19) reported no additional contributions in the group where they assessed late imaging in 66 invasive breast cancers, of which only 3 cases were the ILC.

In the study that Sasada et al. (22) evaluated a total of 1122 invasive breast cancers, 30 of which were ILC, in late imaging, the value we defined as $\Delta$ in our study is expressed as retention index (RI). Although there was no significant difference in our study, SUV max in the HER-2 positive group is higher than the group where MTV and TLG median values were negative (Table 2).

In the study investigating the contribution of late imaging in 53 invasive breast cancers where only 2 cases were ILC, it was reported that there was low ER positivity and high HER-2 expression in the group with high RI (24). In our study, it was shared in Table 3 that the ER negative cases were more significant in the SUV $V_{\max }$ and the SUV $V_{\text {max }}$ MTV and TLG median values were higher than the positive group.

In a study of Lee et al. (27), late imaging showed more significant correlation with prognostic factors in 38 invasive breast cancer cases, 2 of which were ILC. A similar correlation has been reported even when the late image was taken earlier (100 minimum) (26). This result will shorten the total examination period and can be taken into consideration in the next studies. In this lowincidence patient group, it is also possible to explain the lack of a statistically significant correlation between primary malignancy tissue analysis values and histopathological variables, since we did not have enough cases to reach statistical significance in our study.

\section{CONCLUSION}

In our study, it is foreseen that in the ILC, which has low FDG-PET sensitivity, the information obtained from the contralateral breast parenchyma and especially lateral image in the dorsal breast tissue, will contribute significantly. No statistically significant correlation was found with histopathological variables. However, parallel results were observed when compared to studies mostly composed of IDC patients. $\triangle$-TLG is high in the group with lymph node metastasis; in HER-2 positive and ER negative cases, SUV max $_{1}$ MTV and TLG median values are higher than HER-2 negative and ER positive groups. This important information needs to be confirmed by meta-analyzes or multicentre studies where the number of cases will be higher.

Table 2. Metabolic parameters and rate of change of primary malignancy and control interests

\begin{tabular}{|c|c|c|c|c|c|c|c|c|c|}
\hline Average (range) & s-SUV ${ }_{\max }$ & g-SUV $V_{\max }$ & $\Delta-\mathrm{SUV}_{\max }$ & s-MTV & g-MTV & $\Delta$-MTV & s-TLG & g-TLG & $\Delta$-TLG \\
\hline $\begin{array}{l}\text { Primary } \\
\text { malignancy }\end{array}$ & $5.11^{\star}(21.58)$ & $7.59(36.10)$ & $49(33)$ & $4.74(17.18)$ & $4.70(16.69)$ & $-1(70)$ & $9.56(33.08)$ & $10.71(21.31)$ & $1(11)$ \\
\hline Control & 1.04 (1.79) & $0.93(4.01)$ & $-11(9.51)$ & $2.40(2.95)$ & $2.24(2.66)$ & $-1(66)$ & 3.88 (1.31) & $3.06(2.30)$ & $-2(16)$ \\
\hline $\mathrm{p}$ & $<0.000 * \star$ & $<0.000$ & $<0.000$ & 0.36 & 0.83 & 0.36 & 0.049 & 0.04 & 0.06 \\
\hline
\end{tabular}




\begin{tabular}{|c|c|c|c|c|c|c|c|c|}
\hline$\Delta-T L G$ & $\begin{array}{l}16(123) \\
8(152)\end{array}$ & $\begin{array}{l}12(123) \\
9(152)\end{array}$ & $\begin{array}{l}8(122) \\
12(123)\end{array}$ & $\begin{array}{l}18(152) \\
10(123)\end{array}$ & $\begin{array}{l}29(39) \\
9(111) \\
18(152)\end{array}$ & $\begin{array}{l}15(39) \\
23(199) \\
-5(40)\end{array}$ & $\begin{array}{l}9(152) \\
16(123)\end{array}$ & $\begin{array}{l}19(76) \\
8(199)\end{array}$ \\
\hline g-TLG & $\begin{array}{l}10.81(41.11) \\
7.16(19.16)\end{array}$ & $\begin{array}{l}8.41(41.11) \\
7.50(13.47)\end{array}$ & $\begin{array}{l}8.89(11.97) \\
7.33(42.26)\end{array}$ & $\begin{array}{l}4.55(12.26) \\
7.50(41.11)\end{array}$ & $\begin{array}{l}5.60(3.80) \\
11.96(41.11) \\
3.29(32.27)\end{array}$ & $\begin{array}{l}6.26(5.96) \\
11.96(42.38) \\
8.02(32.14)\end{array}$ & $\begin{array}{l}7.16(19.16) \\
11.60(41.11)\end{array}$ & $\begin{array}{l}5.02(12.13) \\
10.42(42.38)\end{array}$ \\
\hline s-TLG & $\begin{array}{l}8.84(9.21) \\
6.86(19.92)\end{array}$ & $\begin{array}{l}8.45(29.21) \\
6.86(12.43)\end{array}$ & $\begin{array}{l}8.25(11.57) \\
7.49(30.66)\end{array}$ & $\begin{array}{l}4.27(9.52) \\
8.13(29.21)\end{array}$ & $\begin{array}{l}4.68(4.36) \\
9.56(26.41) \\
2.48(28.48)\end{array}$ & $\begin{array}{l}5.70(5.63) \\
9.56(30.92) \\
8.51(28.22)\end{array}$ & $\begin{array}{l}6.86(19.92) \\
10.30(29.21)\end{array}$ & $\begin{array}{l}4.55(9.26) \\
10.19(30.92)\end{array}$ \\
\hline$\triangle$-MTV & $\begin{array}{l}2(172) \\
-12(102)\end{array}$ & $\begin{array}{l}4(172) \\
-12(102)\end{array}$ & $\begin{array}{l}13(50) \\
-5(172)\end{array}$ & $\begin{array}{l}7(103) \\
-1(172)\end{array}$ & $\begin{array}{l}-14(3) \\
1(107) \\
14(138)\end{array}$ & $\begin{array}{l}-2(29) \\
1(172) \\
-13(68)\end{array}$ & $\begin{array}{l}-1(103) \\
4(172)\end{array}$ & $\begin{array}{l}2(138) \\
1(137)\end{array}$ \\
\hline g-MTV & $\begin{array}{l}3.57(17.03) \\
1.65(17.79)\end{array}$ & $\begin{array}{l}3.67(17.19) \\
1.36(6.98)\end{array}$ & $\begin{array}{l}6.55(6.98) \\
2.17(17.19)\end{array}$ & $\begin{array}{l}3.17(6.98) \\
2.69(17.19)\end{array}$ & $\begin{array}{l}2.68(2.64) \\
4.65(17.19) \\
1.56(17.63)\end{array}$ & $\begin{array}{l}3.34(3.29) \\
1.58(17.79) \\
4.33(16.64)\end{array}$ & $\begin{array}{l}2.69(17.79) \\
3.11(17.03)\end{array}$ & $\begin{array}{l}2.69(4.31) \\
3.56(17.79)\end{array}$ \\
\hline s-MTV & $\begin{array}{l}4.52(14.46) \\
2.70(14.80)\end{array}$ & $\begin{array}{l}4.52(14.46) \\
2.15(6.21)\end{array}$ & $\begin{array}{l}6.23(6.56) \\
3.51(14.46)\end{array}$ & $\begin{array}{l}3.69(6.21) \\
4.32(14.46)\end{array}$ & $\begin{array}{l}3.08(2.95) \\
4.72(13.84) \\
13.93(138.44)\end{array}$ & $\begin{array}{l}3.34(2.95) \\
4.72(14.80)-13.10(67.91)\end{array}$ & $\begin{array}{l}2.70(14.80) \\
4.52(14.46)\end{array}$ & $\begin{array}{l}2.37(4.38) \\
5.06(15.29)\end{array}$ \\
\hline$\Delta-S U V_{\max }$ & $\begin{array}{l}53(108) \\
49(43)\end{array}$ & $\begin{array}{l}49(108) \\
57(43)\end{array}$ & $\begin{array}{l}57(23) \\
49(108)\end{array}$ & $\begin{array}{l}48(35) \\
49(108)\end{array}$ & $\begin{array}{l}48(43) \\
49(96) \\
53(59)\end{array}$ & $\begin{array}{l}43(43) \\
57(90) \\
36(55)\end{array}$ & $\begin{array}{l}49(47) \\
54(108)\end{array}$ & $\begin{array}{l}49(43) \\
53(108)\end{array}$ \\
\hline $\mathrm{g}-\mathrm{SUV} \mathrm{V}_{\max }$ & $\begin{array}{l}5.93(34.90) \\
3.93(5.49)\end{array}$ & $\begin{array}{l}5.93(9.24) \\
3.99(36.10)\end{array}$ & $\begin{array}{l}4.35(4.28) \\
4.40(35.57)\end{array}$ & $\begin{array}{l}3.81(1.76) \\
4.99(35.57)\end{array}$ & $\begin{array}{l}4.24(0.62) \\
6.87(35.57) \\
4.13(9.77)\end{array}$ & $\begin{array}{l}4.77(4.08) \\
4.02(36.10) \\
6.21(8.72)\end{array}$ & $\begin{array}{l}4.02(5.49) \\
9.91(34.90)\end{array}$ & $\begin{array}{l}4.25(4.37) \\
5.61(36.10)\end{array}$ \\
\hline $\mathrm{s}-\mathrm{SUV} \mathrm{V}_{\max }$ & $\begin{array}{l}4.16(21.52)^{\star} \\
2.69(4.21)\end{array}$ & $\begin{array}{l}4.16(9.14) \\
2.85(21.58)\end{array}$ & $\begin{array}{l}3.24(2.71) \\
2.99(21.52)\end{array}$ & $\begin{array}{l}2.50(1.59) \\
3.96(21.52)\end{array}$ & $\begin{array}{l}2.90(0.43) \\
4.36(21.52) \\
2.59(9.20)\end{array}$ & $\begin{array}{l}3.54(2.33) \\
2.85(21.58) \\
4.54(8.70)\end{array}$ & $\begin{array}{l}2.85(4.21) \\
6.99(21.52)\end{array}$ & $\begin{array}{l}2.86(2.87) \\
3.80(21.58)\end{array}$ \\
\hline \multirow[b]{2}{*}{ Patients ( $n$ ) } & T-stage & $\mathrm{N}$-stage & ER & PR & $\begin{array}{l}\text { Nuclear } \\
\text { grade }\end{array}$ & $\begin{array}{l}\text { Histological } \\
\text { grade }\end{array}$ & HER-2 & Ki-67 \\
\hline & $\begin{array}{l}\text { T1 (10) } \\
\text { T2-T3 (7) }\end{array}$ & $\begin{array}{l}\text { No (10) } \\
\text { N1 (7) }\end{array}$ & $\begin{array}{l}-(3) \\
+(14)\end{array}$ & $\begin{array}{l}-(4) \\
+(13)\end{array}$ & $\begin{array}{l}1(2) \\
2(9) \\
3(6)\end{array}$ & $\begin{array}{l}1(4) \\
2 \text { (9) } \\
3(4)\end{array}$ & $\begin{array}{l}-(11) \\
+(6)\end{array}$ & $\begin{array}{l}<14(7) \\
\geq 14(10)\end{array}$ \\
\hline
\end{tabular}

Ethics Committee Approval: Retrospective study.

Informed Consent: Patient consent could not be obtained due to the retrospective study structure.

Peer-review: Externally peer-reviewed.

Author Contributions: Concept - F.O.F., H.S.; Design - F.O.F., H.S.; Data Collection and/or Processing - F.O.F., H.S.; Analysis and/ or Interpretation - F.O.F.; Literature Search - F.O.F.; Writing Manuscript - F.O.F.; Critical Review - F.O.F., H.S.

Conflict of Interest: The authors have no conflict of interest to declare.

Financial Disclosure: The authors declared that this study has received no financial support.

\section{REFERENCES}

1. Li Cl, Anderson BO, Porter P, Holt SK, Daling JR, Moe RE. Changing incidence rate of invasive lobular breast carcinoma among older women. Cancer 2000; 88: 2561-9.

2. Albert ML, Gao Y, Moy L. Role of Breast MRI in Patients with Newly Diagnosed Breast Cancer. Current Breast Cancer Reports 2016; 8: 80-9.

3. Scheidhauer K, Walter C, Seemann MD. FDG PET and other imaging modalities in the primary diagnosis of suspicious breast lesions. Eur $\mathrm{J}$ Nucl Med Mol Imaging 2004; 31 (Suppl 1): 70-9.

4. Nieweg OE, Kim EE, Wong WH, Broussard WF, Singletary SE, Hortobagyi GN, et al. Positron Emission Tomography with Fluorine- 18- Deoxyglucose in the Detection and Staging of Breast Cancer. Cancer 1993; 71: 3920-5.
5. Dong A, Wang Y, Lu J, Zuo C. Spectrum of the breast lesions with increased 18F-FDG uptake on PET/CT. Clin Nucl Med 2016; 41: 543-57.

6. Buck AK, Schirrmeister $H$, Mattfeldt $T$, Reske SN. Biological characterisation of breast cancer by means of PET. Eur J Nucl Med Mol Imaging 2004; 31(Suppl 1): 80-7.

7. Bos R, van Der Hoeven JJ, van Der Wall E, van Der Groep P, van Diest PJ, Comans EF, et al. Biologic correlates of (18) fluorodeoxyglucose uptake in human breast cancer measured by positron emission tomography. $J$ Clin Oncol 2002; 20: 379-87.

8. Osborne JR, Port E, Gonen M, Doane A, Yeung H, Gerald W, et al. 18 F-FDG PETof locally invasive breast cancer and association of estrogen receptor status with standardized uptake value: microarray and immunohistochemical analysis. J Nucl Med 2010; 51:543-50.

9. Hogan MP, Goldman DA, Dashevsky B, Riedl CC, Gönen M, Osborne JR, et al. Comparison of 18F-FDG PET/CT for systemic staging of newly diagnosed invasive lobular carcinoma versus invasive ductal carcinoma. J Nucl Med 2015; 56: 1674-80

10. Li Cl, Uribe DJ, Daling JR. Clinical characteristics of different histologic types of breast cancer. Br J Cancer 2005; 93: 1046-52.

11. Groheux $D$, Cochet $A$, Humbert $O$, Alberini JL, Hindié $E$, Mankoff D. 18F-FDG PET/CT for Staging and Restaging of Breast Cancer. J Nucl Med 2016; (Suppl 1): 17-26.

12. Dong A, Wang Y, Lu J, Zuo C. Spectrum of the breast lesions with increased 18F-FDG uptake on PET/CT. Clin Nucl Med 2016; 41: 54357

13. Jung NY, Kim SH, Choi BB, Kim SH, Sung MS. Associations between the standardized uptake value of (18)F-FDG PET/CT and the prognostic 
factors of invasive lobular carcinoma: in comparison with invasive ductal carcinoma. World J Surg Oncol 2015; 13: 113.

14. Choi WH, Yoo IR, O JH, Kim SH, Chung SK. The value of dual-time-point 18F-FDG PET/CT for identifying axillary lymph node metastasis in breast cancer patients. Br J Radiol 2011; 84: 593-9.

15. Hahn S, Hecktor J, Grabellus F, Hartung V, Pöppel T, Kimmig R, et al. Diagnostic accuracy of dual-time-point 18F-FDG PET/CT for the detection of axillary lymph node metastases in breast cancer patients. Acta Radiol 2012; 53: 518-23.

16. Matthiessen LW, Johannesen HH, Skougaard K, Gehl J, Hendel HW. Dual time point imaging fluorine-18 flourodeoxyglucose positron emission tomography for evaluation of large loco-regional recurrences of breast cancer treated with electrochemotherapy. Radiol Oncol 2013; 47: 358-65.

17. Zytoon AA, Murakami K, El-Kholy MR, El-Shorbagy E, Ebied O. Breast cancer with low FDG uptake: characterization by means of dual-time point FDG-PET/CT. Eur J Radiol 2009; 70: 530-8.

18. Houshmand S, Salavati A, Segtnan EA, Grupe P, Høilund-Carlsen PF, Alavi A. Dual-time-point Imaging and Delayed-time-point Fluorodeoxyglucose-PET/Computed Tomography Imaging in Various Clinical Settings. PET Clin 2016; 11: 65-84.

19. Garcia-Vicente AM, Molina D, Pérez-Beteta J, Amo-Salas M, MartínezGonzález A, Bueno G, et al. Textural features and SUV-based variables assessed by dual time point 18F-FDG PET/CT in locally advanced breast cancer. Ann Nucl Med 2017; 31: 726-35.

20. Garcia-Vicente AM, Pérez-Beteta J, Pérez-García VM, Molina D, JiménezLondoño GA, Soriano-Castrejón A, et al. Metabolic Tumor Burden Assessed by Dual Time Point [18F] FDG PET/CT in Locally Advanced Breast Cancer: Relation with Tumor Biology. Mol Imaging Biol 2017; 19: 636-44.

21. Hildebrandt MG, Gerke O, Baun C, Falch K, Hansen JA, Farahani ZA, et al. [18F] Fluorodeoxyglucose (FDG)-Positron Emission Tomography (PET)/Computed Tomography (CT) in Suspected Recurrent Breast Cancer: A Prospective Comparative Study of Dual-Time-Point FDG-PET/ CT, Contrast-Enhanced CT, and Bone Scintigraphy. J Clin Oncol 2016; 34: 1889-97.

22. Sasada S, Masumoto N, Suzuki E, Sueoka S, Goda N, Kajitani K, et al. Prediction of biological characteristics of breast cancer using dual-phase FDG PET/CT. Eur J Nucl Med Mol Imaging 2019; 46: 831-7.
23. Yoo J, Kim BS, Chung J, Yoon HJ. Percentage change of primary tumor on 18F-FDG PET/CT as a prognostic factor for invasive ductal breast cancer with axillary lymph node metastasis: Comparison with MRI. Medicine (Baltimore) 2017; 96: 7657.

24. Ozen A, Altinay S, Ekmekcioglu O, Albayrak R, Muhammedoglu A, Yigitbas $\mathrm{H}$, et al. Dual-Time 18F-FDG PET/CT Imaging in Initial Locoregional Staging of Breast Carcinoma: Comparison with Conventional Imaging and Pathological Prognostic Factors. Indian J Surg 2016; 78: 382-9.

25. Moon H, Noh WC, Kim HA, Kim EK, Park KW, Lee SS, et al. The Relationship Between Estrogen Receptor, Progesterone Receptor and Human Epidermal Growth Factor Receptor 2 Expression of Breast Cancer and the Retention Index in Dual Phase (18)F-FDG PET/CT. Nucl Med Mol Imaging 2016; 50: 246-54.

26. Caprio MG, Cangiano A, Imbriaco M, Soscia F, Di Martino G, Farina A, et al. Dual-time-point [18F]-FDG PET/CT in the diagnostic evaluation of suspicious breast lesions. Radiol Med 2010; 115: 215-24.

27. Lee JY, Song HS, Choi JH, Hyun CL. Dual-Time-Point FDG Uptake Correlates with Prognostic Factors of Invasive Breast Cancer: Clinical Usefulness of Early Delayed Scanning. Diagnostics (Basel) 2019; 9: 40.

28. Rakha EA, El-Sayed ME, Powe DG, Green AR, Habashy H, Grainge MJ, et al. Invasive lobular carcinoma of the breast: response to hormonal therapy and outcomes. Eur J Cancer 2008; 44: 73-83.

29. $\mathrm{Li} \mathrm{Cl}$, Anderson BO, Daling JR, Moe RE. Trends in incidence rates of invasive lobular and ductal breast carcinoma. JAMA 2003; 1: 421-4.

30. Helvie MA, Paramagul C, Oberman HA, Adler DD. Invasive lobular carcinoma. Imaging features and clinical detection. Invest Radiol 1993; 28: 202-7.

31. Basu S, Chen W, Tchou J, Mavi A, Cermik T, Czerniecki B, et al. Comparison of triple-negative and estrogen receptor-positive/progesterone receptor-positive/HER2-negative breast carcinoma using quantitative fluorine-18 fluorodeoxyglucose/positron emission tomography imaging parameters: a potentially useful method for disease characterization. Cancer 2008; 112: 995-1000.

32. Crippa F, Seregni E, Agresti R, Chiesa C, Pascali C, Bogni A, et al. Association between [18F]-fluorodeoxyglucose uptake and postoperative histopathology, hormone receptor status, thymidine labeling index, and p53 in primary breast cancer: a preliminary observation. Eur J Nucl Med 1998; 25: 1429-34. 